\title{
A systematic review of the efficacy of self-management programs for increasing physical activity in community-dwelling adults with acquired brain injury (ABI)
}

Taryn M Jones ${ }^{1,3^{*}}$, Catherine M Dean ${ }^{1,3}$, Julia M Hush ${ }^{1,3}$, Blake F Dear ${ }^{2,3}$ and Nickolai Titov ${ }^{2,3}$

\begin{abstract}
Background: Individuals living with acquired brain injury, typically caused by stroke or trauma, are far less likely to achieve recommended levels of physical activity for optimal health and well-being. With a growing number of people living with chronic disease and disability globally, self-management programs are seen as integral to the management of these conditions and the prevention of secondary health conditions. However, to date, there has been no systematic review of the literature examining the efficacy of self-management programs specifically on physical activity in individuals with acquired brain injury, whether delivered face-to-face or remotely. Therefore, the purpose of this review is to evaluate the efficacy of self-management programs in increasing physical activity levels in adults living in the community following acquired brain injury. The efficacy of remote versus face-to-face delivery was also examined.
\end{abstract}

Methods: A systematic review of the literature was conducted. Electronic databases were searched. Two independent reviewers screened all studies for eligibility, assessed risk of bias, and extracted relevant data.

Results: Five studies met the inclusion criteria for this review. Studies were widely heterogeneous with respect to program content and delivery characteristics and outcomes, although all programs utilized behavioral change principles. Four of the five studies examined interventions in which physical activity was a component of a multifaceted intervention, where the depth to which physical activity specific content was covered, and the extent to which skills were taught and practiced, could not be clearly established. Three studies showed favorable physical activity outcomes following self-management interventions for stroke; however, risk of bias was high, and overall efficacy remains unclear. Although not used in isolation from face-to-face delivery, remote delivery via telephone was the predominant form of delivery in two studies with support for its inclusion in self-management programs for individuals following stroke.

Conclusions: The efficacy of self-management programs in increasing physical activity levels in community-dwelling adults following acquired brain injury (ABI) is still unknown. Research into the efficacy of self-management programs specifically aimed at improving physical activity in adults living in the community following acquired brain injury is needed. The efficacy of remote delivery methods also warrants further investigation.

Systematic review registration: PROSPERO CRD42013006748

Keywords: Management, Exercise, Trauma, Cerebrovascular accident, Remote delivery, Internet

\footnotetext{
* Correspondence: taryn.jones@mq.edu.au

'Department of Health Professions, Macquarie University, Ground Floor,

75 Talavera Rd, Sydney, NSW 2109, Australia

${ }^{3}$ Centre for Physical Health, Macquarie University, Ground Floor, 75 Talavera

Rd, Sydney 2109, Australia

Full list of author information is available at the end of the article
}

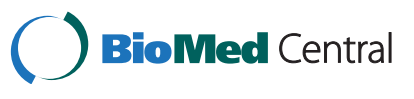

(c) 2015 Jones et al.; licensee BioMed Central. This is an Open Access article distributed under the terms of the Creative Commons Attribution License (http://creativecommons.org/licenses/by/4.0), which permits unrestricted use, distribution, and reproduction in any medium, provided the original work is properly credited. The Creative Commons Public Domain Dedication waiver (http://creativecommons.org/publicdomain/zero/1.0/) applies to the data made available in this article, unless otherwise stated. 


\section{Background}

Acquired brain injury (ABI) refers to any damage to the brain that occurs after birth with common causes including stroke or trauma [1]. ABI is a significant public health issue globally. Stroke is one of the greatest causes of disease burden globally [2] and is one of the main non-communicable diseases of public health importance [3], while traumatic brain injuries are the leading cause of disability in children and young adults globally [3].

Individuals with ABI often have more complex disabilities than other groups with disability [1] and often face many barriers in increasing their levels of physical activity, such as mobility impairments, fear, pain, financial costs, transport difficulties, and limited local specialist services [4-9]. Physical activity interventions are effective in improving physical, psychosocial, and cognitive status; however, maintaining these improvements once intervention ceases is challenging, and physical activity participation levels after ABI remain low [5,10-16].

Physical inactivity both causes and accelerates chronic diseases, such as cardiovascular disease, diabetes, and cancer [17], with individuals with $\mathrm{ABI}$ at elevated risk [1]. In fact, the World Health Organization (WHO) report that almost a third of all strokes occur in those who have previously had a stroke [3]. Despite this, ABI is often a lower priority for research and services than conditions with a similar, or lower, public health priority [2] and there is a significant lack of physical activity promotion programs targeting those with ABI $[18,19]$.

The WHO has argued for nations to do more to prevent chronic disease [20], particularly through the use of strategies to increase physical activity [21]. Selfmanagement is seen as integral to optimal chronic disease prevention and management [22]. Given that physical inactivity is a significant modifiable risk factor for chronic diseases, such as stroke [17,23], increasing the self-management of physical activity specifically in individuals with $\mathrm{ABI}$ appears crucial for the long-term prevention of further morbidity and mortality.

Self-management ultimately reflects an individual's responsibility for the day-to-day management of their disease including decisions regarding engagement in healthy behaviors [24]. The most promising way of supporting self-management is to empower and activate people, primarily through the expansion of skills, such as problem-solving and decision-making, therefore building self-efficacy to alter long-term behaviors [24,25]. There is considerable evidence that self-management programs result in better long-term outcomes for people with chronic diseases [26-29], including programs for individuals with ABI, specifically stroke [30,31]. Despite this, many people with $\mathrm{ABI}$ do not receive and cannot access self-management programs. For example, in the National Stroke Audit undertaken in Australia in 2012, only $25 \%$ of stroke survivors were informed about selfmanagement programs, a decline from 40\% in 2008 [32].

Implementation of self-management programs may be enhanced through the use of innovative modes of remote program delivery. Compared with face-to-face delivery, remote delivery modes, such as telephone and the Internet, may increase accessibility for those who face multiple barriers to accessing optimal health care [33], such as cost, mobility restrictions, or service availability in rural or remote regions. Delivery of selfmanagement programs via the Internet has been used with success in a variety of populations, such as chronic pain [34], anxiety and depression [35-37], post-traumatic stress disorder [38], arthritis [39], and cerebral palsy [40]. The potential for remote-based delivery methods to be utilized to increase physical activity has also been highlighted by Foster and colleagues in a recent Cochrane review [41]. However, to date, there has been no systematic review of the literature examining the efficacy of self-management programs specifically on physical activity in individuals with $\mathrm{ABI}$, whether delivered face-to-face or remotely. Therefore, the objectives of this systematic review were to address the following questions:

1. How effective are self-management programs in improving physical activity in community-dwelling adults with ABI?

2. How effective and acceptable is remote delivery of self-management programs aimed at improving physical activity in community-dwelling adults with ABI?

3. Which features of self-management programs for community-dwelling adults with ABI are associated with the best clinical outcomes and client satisfaction?

\section{Methods}

\section{Study registration}

The systematic review has been conducted and reported using the Preferred Reporting Items for Systematic Reviews and Meta-Analyses (PRISMA) statement guidelines [42]. The Cochrane Collaboration guidelines for reviewing interventions were also closely followed [43]. The protocol of this systematic review has been registered on PROSPERO 2013 (registration number: CRD42013006748) [44] and has been published [45].

\section{Search strategy}

We conducted an extensive search of the literature for articles indexed on MEDLINE, EMBASE, CINAHL, PsycINFO, AMED, Cochrane Central Register of Controlled Trials (CENTRAL), PEDro and Science Citation Index Expanded (SCI-EXPANDED) databases from their 
inception to December 2014. We developed a search strategy in MEDLINE using the following steps: (1) development of keywords by examining relevant key terms used in existing systematic reviews, (2) a thorough examination of the MeSH Database, and (3) expert guidance and review by a specialist librarian. Finally, the search strategy was trialed and refined in order to ensure it was the most effective strategy for this review (Additional file 1). This strategy was then customized for differences in indexing across other databases [45] published to allow for replication [45]. We also screened the reference lists of relevant reviews to identify further studies for potential inclusion in this review. NonEnglish language studies were also considered for inclusion, where a translation could be made available.

\section{Eligibility criteria}

Our eligibility criteria were defined $a$ priori and are outlined in Table 1. ABI was defined as damage to brain occurring after birth. However, for the purpose of this review, studies examining individuals with degenerative ABI (for example Parkinson's disease or multiple sclerosis), cerebral palsy, developmental delay, fetal alcohol spectrum disorder (FASD), concussion, or transient ischaemic attacks (TIA) were not included. There was no limit based on time since injury. In studies where it was unclear that participants

Table 1 Inclusion criteria

\begin{tabular}{ll}
\hline Inclusion \\
\hline Study design & Randomized controlled trial (RCT) \\
& Quasi-randomized controlled trial (QRCT) - for example, \\
& allocation by date of birth, location, medical record \\
& number \\
Participants & Adults (18 years and over) \\
& Non-degenerative acquired brain injury (ABI) \\
& Currently living in the community \\
& Are not undergoing significant medical or surgical \\
& intervention \\
& Self-management program which: \\
Intervention & Includes at least one of the following components: \\
& problem-solving, goal-setting, decision-making, \\
& self-monitoring, coping strategies, or another \\
& approach to facilitate behavior change; \\
& Has at least a component of the program focusing \\
& on increasing physical activity. \\
& Must include at least one of the following: \\
& A measure of physical activity: either from a physical \\
activity monitoring device (for example, accelerometer, \\
pedometer) or a self-report measure; \\
And/or \\
A study outcome associated specifically with physical \\
activity, for example, physical activity self-efficacy, \\
physical self-concept, or stages of change in relation \\
to physical activity.
\end{tabular}

met our inclusion criteria, we contacted the study author for verification. We excluded any studies where verification could not be made by the authors.

\section{Identification of relevant studies}

Two authors (TM), CMD) independently assessed the titles and abstracts of all records identified from the searches of the electronic databases. Records identified as not meeting the eligibility criteria were excluded. The full text of the remaining studies was obtained and reviewed for eligibility independently by the same two authors. In one case, an independent translation from Korean to English was required in order to assess eligibility. At each stage of the process, records were marked 'accept', 'reject', or 'unsure'. Those records marked 'unsure', or where disagreements between reviewers arose, discussion between the reviewers was undertaken in order to reach consensus.

\section{Data extraction}

Data from included studies were extracted independently by two reviewers (TMJ, CMD) using a standardized data extraction form. Data were extracted for all available time points on the outcome measures that were defined a priori as per our protocol [45]. We also recorded any adverse outcomes that were reported in the studies included in this review.

\section{Risk of bias assessment}

Two reviewers (TMJ, CMD) independently assessed the risk of bias for each included study using The Cochrane Collaboration's tool for assessing bias [46]. A summary of risk of bias across all studies within each domain was also performed.

\section{Data synthesis}

A meta-analysis was not possible due to significant heterogeneity of the outcome measures utilized in each of the studies. Instead, a detailed summary of the results from the individual studies was collated into a table, and a systematic narrative synthesis was conducted. A comparison of remote-delivery methods with traditional face-to-face delivery methods was also not possible because all studies included in the review included a faceto-face delivery mode for at least some portion of their program.

\section{Results}

Results of the search

Our search of electronic databases generated 3,654 references. An additional 20 references were obtained from handsearching the reference lists of nine systematic reviews identified from the electronic searches [31,47-54]. Following duplicate removal and screening of titles and 
abstracts, 124 full-text articles were assessed for eligibility. Assessment resulted in 119 references being excluded with reasons outlined in Figure 1. Five studies met the eligibility criteria and were included in this review [55-59].

\section{Details of included studies}

Details of the included studies are reported in Table 2. Four of these studies were published in English. The fifth study was published in Korean [58], and an independent translation was obtained. Two studies were performed in the USA [55,56], one in Australia [57], one in Korea [58], and one in Hong Kong [59]. The interventions examined in each study varied in regard to both content and delivery characteristics. The studies also vary greatly in regard to outcome measures used.

\section{Demographic characteristics}

Demographic details of study participants are outlined in Table 2. Four of the studies examined participants following stroke [56-59], while one studied participants with traumatic brain injury (TBI) [55]. Most studies included in this review had relatively small sample sizes, although one study had 190 participants [59]. The mean age of all stroke participants $(n=336)$ was 64.42 $(\mathrm{SD}=10.81)$ years, while the TBI participants $(n=74)$ had a mean age of $43.83(\mathrm{SD}=15.34)$ years. A measure of severity of $\mathrm{ABI}$ was reported in two of the five studies $[55,56]$. Four out of the five studies $[55,56,58,59]$ reported eligibility criteria that required cognitive and communication skills to be adequate for participation in a self-management program; however, assessment of this criterion differed in each study.

\section{Intervention content}

The content of the intervention programs applied in each of the studies is also summarized in Table 2. The extent to which physical activity was specifically addressed and targeted differed between each program. In

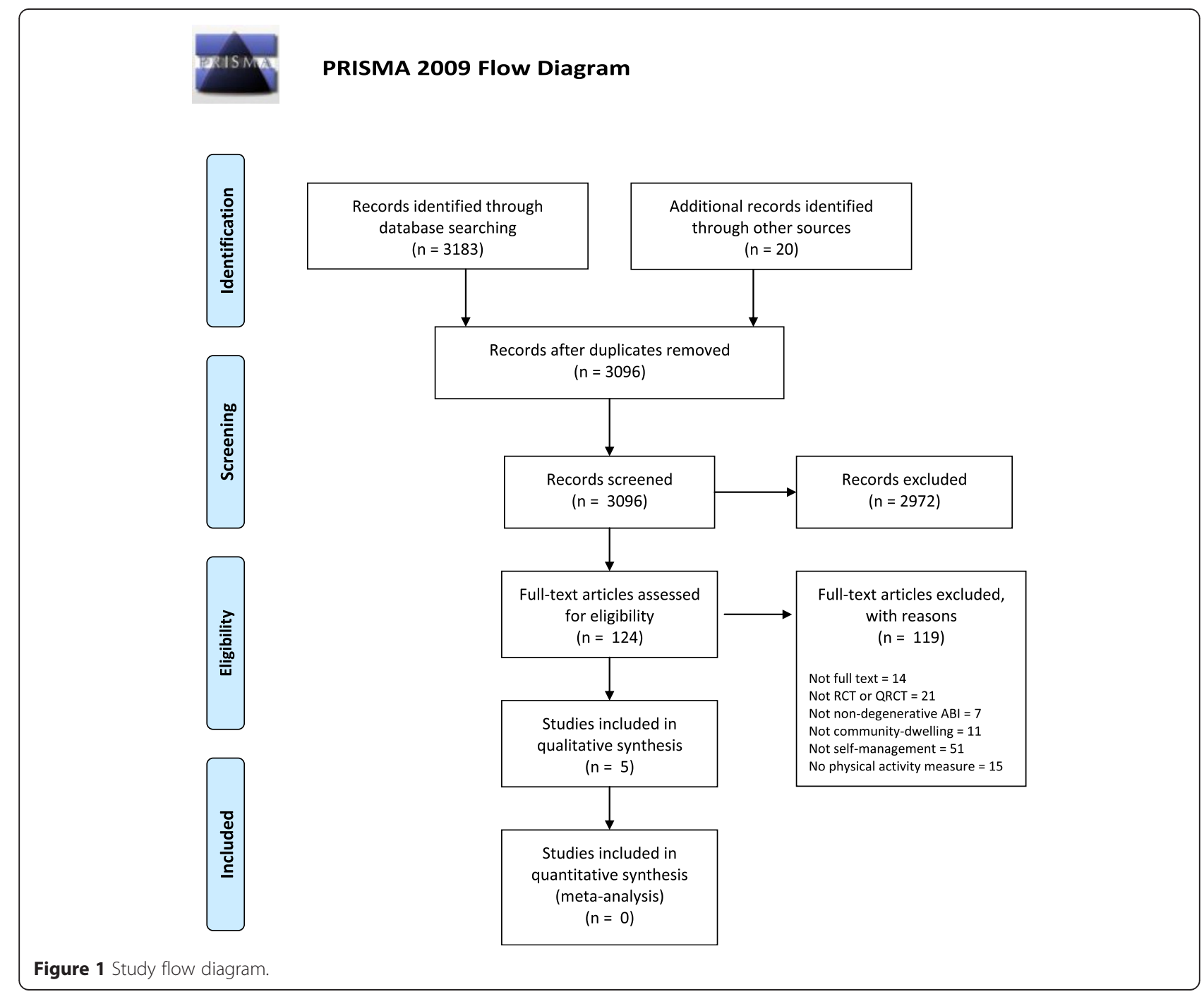


Table 2 Summary of included studies

\begin{tabular}{|c|c|c|c|c|c|c|c|}
\hline \multirow{2}{*}{$\begin{array}{l}\text { Study (year, } \\
\text { country, } \\
\text { study design) }\end{array}$} & \multirow{2}{*}{$\begin{array}{l}\text { Type } \\
\text { of } A B I\end{array}$} & \multirow{2}{*}{ Participants } & \multicolumn{3}{|l|}{ Intervention } & \multirow[t]{2}{*}{ Control } & \multirow{2}{*}{$\begin{array}{l}\text { Follow-up } \\
\text { assessments/ } \\
\text { Drop outs/ } \\
\text { Sample size } \\
\text { analyzed }\end{array}$} \\
\hline & & & Content & Delivery characteristics & $\begin{array}{l}\text { Theoretical } \\
\text { model }\end{array}$ & & \\
\hline \multirow{13}{*}{$\begin{array}{l}\text { Brenner et al. } \\
\text { (2012, USA, } \\
\text { RCT) }\end{array}$} & \multirow[t]{13}{*}{$\mathrm{TBI}$} & Sample size: $n=74$ & \multirow{11}{*}{$\begin{array}{l}\text { 'Health and Wellness therapy group': } \\
\text { program provided information to } \\
\text { facilitate health promotion while } \\
\text { emphasizing self-assessment to help } \\
\text { participants to set individualized goals, } \\
\text { problem-solve to reduce barriers, and } \\
\text { strategies to enhance self-efficacy. } \\
\text { Program aimed to take advantage } \\
\text { of the group process, as well as } \\
\text { encouraging participants to involve } \\
\text { an identified resource person to assist } \\
\text { in self-assessment and behavior change. }\end{array}$} & \multirow{5}{*}{$\begin{array}{l}\text { Duration: } 12 \times 1.5 \text { h sessions; } \\
1 \text { session/week for } 12 \text { weeks }\end{array}$} & TTM & \multirow[t]{13}{*}{ Wait-list control } & \multirow{4}{*}{$\begin{array}{l}\text { Follow-up: } \\
3 \text { months and } \\
6 \text { months }\end{array}$} \\
\hline & & $\mathrm{IG}=37 ; \mathrm{CG}=37$ & & & SCT & & \\
\hline & & Gender: & & & & & \\
\hline & & Male: IG = 29 (78.4\%) & & & & & \\
\hline & & $C G=32(86.5 \%)$ & & & & & Drop outs: $n=9$ \\
\hline & & Female: IG = 8 (21.6\%) & & \multirow{3}{*}{$\begin{array}{l}\text { Delivery mode: face-to-face } \\
\text { group sessions with } \\
\text { workbook }\end{array}$} & & & IG: $n=7 ;$ CG: $n=2$ \\
\hline & & $C G=5(13.5 \%)$ & & & & & Sample analyzed: \\
\hline & & Mean age (years): & & & & & $n=65$ \\
\hline & & $\mathrm{IG}=43.46(\mathrm{SD} 16.00)$ & & \multirow{5}{*}{$\begin{array}{l}\text { Facilitators: social worker, } \\
\text { speech pathologist, physical } \\
\text { therapist, and nurse who } \\
\text { rotated in groups of } 2\end{array}$} & & & IG: $n=30 ; C G: n=35$ \\
\hline & & $C G=44.14(S D$ 14.97) & & & & & \\
\hline & & $\begin{array}{l}\text { Mean }(S D) \text { time since } \\
A B I \text { (years): }\end{array}$ & & & & & \\
\hline & & $\mathrm{IG}=11.74(13.80)$ & \multirow{2}{*}{$\begin{array}{l}\text { Physical activity specific content: Two } \\
\text { sessions (sessions } 5 \text { and } 6 \text { ) focus on } \\
\text { fitness self-assessment, getting started } \\
\text { with physical exercise, measuring resting } \\
\text { heart rate, benefits of exercise. }\end{array}$} & & & & \\
\hline & & $C G=12.50(13.75)$ & & & & & \\
\hline \multirow{2}{*}{$\begin{array}{l}\text { Damush et al. } \\
\text { (2011, USA }\end{array}$} & \multirow{12}{*}{ Stroke } & Sample size: $n=66$ & \multirow{10}{*}{$\begin{array}{l}\text { 'Stroke self-management program': The } \\
\text { sessions followed a standardized manual } \\
\text { based on the CDSMP with a focus on } \\
\text { enhancing self-efficacy to manage } \\
\text { symptoms and foster behavior change. } \\
\text { Techniques employed included goal } \\
\text { setting and behavioral contracting. } \\
\text { Telephone follow-up focused on } \\
\text { reinforcing, monitoring, and adjusting } \\
\text { the goals and self-management strategies. }\end{array}$} & \multirow{7}{*}{$\begin{array}{l}\text { Duration: } 6 \text { sessions over a } \\
\text { 3-month period ( } 3 \text { face-to-face } \\
\text { and } 3 \text { via telephone) as well as } \\
\text { biweekly telephone follow-up. } \\
\text { Average session length was } \\
20 \text { min. }\end{array}$} & \multirow{7}{*}{$\begin{array}{l}\text { SCT } \\
\text { (specifically } \\
\text { self-efficacy) }\end{array}$} & \multirow{12}{*}{$\begin{array}{l}\text { Written patient educational } \\
\text { materials on stroke warning } \\
\text { signs and pamphlets from the } \\
\text { American Stroke Association } \\
\text { on prevention of secondary } \\
\text { strokes. Telephone calls were } \\
\text { also made by the case } \\
\text { manager on the same schedule } \\
\text { as IG to discuss how participant } \\
\text { felt that day. }\end{array}$} & \multirow{4}{*}{$\begin{array}{l}\text { Follow-up: } 3 \text { months } \\
\text { and }\end{array}$} \\
\hline & & Gender: & & & & & \\
\hline \multirow[t]{10}{*}{$\mathrm{RCT})$} & & Male: IG = 30 (100\%) & & & & & \\
\hline & & $C G=32(97.0 \%)$ & & & & & \\
\hline & & Female: IG = $0(0 \%)$ & & & & & 6 months \\
\hline & & $C G=1(3.0 \%)$ & & & & & Drop outs: $n=3$ \\
\hline & & & & & & & $\begin{array}{l}\text { No info regarding } \\
\text { groups }\end{array}$ \\
\hline & & Mean age (years): & & & & & Sample analyzed: \\
\hline & & $\mathrm{IG}=67.3(\mathrm{SD} 12.4)$ & & & & & $n=63$ \\
\hline & & $C G=64.0(S D 8.4)$ & & \multirow{2}{*}{$\begin{array}{l}\text { Delivery mode: face-to-face } \\
\text { and telephone with } \\
\text { standardized manual }\end{array}$} & & & IG: $n=30 ; C G: n=33$ \\
\hline & & \multirow{2}{*}{$\begin{array}{l}\text { Time since ABI: participants } \\
\text { identified during hospital } \\
\text { admission for ischemic } \\
\text { stroke. }\end{array}$} & \multirow{2}{*}{$\begin{array}{l}\text { Physical activity specific content: } 2 \text { topics } \\
\text { out of } 24 \text { focused on physical activity } \\
\text { specifically - 'Getting Active at Home' and } \\
\text { 'Walking for Health'. An additional topic } \\
\text { on rehabilitation included discussion on } \\
\text { following prescribed exercises at home. }\end{array}$} & & & & \\
\hline & & & & $\begin{array}{l}\text { Facilitators: a nurse, a } \\
\text { physician assistant, and a } \\
\text { master's level social scientist }\end{array}$ & & & \\
\hline
\end{tabular}


Table 2 Summary of included studies (Continued)

\begin{tabular}{|c|c|c|c|c|c|c|c|}
\hline \multirow{14}{*}{$\begin{array}{l}\text { Gill and } \\
\text { Sullivan (2011, } \\
\text { AustraliaQRCT) }\end{array}$} & \multirow{14}{*}{ Stroke } & Sample size: $n=26$ & \multirow{11}{*}{$\begin{array}{l}\text { 'Stay Active and Stop Stroke (SASS)': } \\
\text { Intervention targets exercise beliefs with } \\
\text { didactic instruction and group-based } \\
\text { activities. Session } 1 \text { aimed to increase } \\
\text { stroke knowledge and highlight risk } \\
\text { factors. Session } 2 \text { aimed to facilitate a } \\
\text { change in beliefs. Session } 3 \text { intended to } \\
\text { strengthen motivation by illustrating } \\
\text { decisional balance processes. Participants } \\
\text { identified personal barriers to increasing } \\
\text { physical activity, generated possible } \\
\text { solutions, and prepared personal activity } \\
\text { goals. }\end{array}$} & \multirow{4}{*}{$\begin{array}{l}\text { Duration: } 3 \times 1 \text { h sessions, } \\
\text { 1/week for } 3 \text { weeks. }\end{array}$} & eHBM & \multirow[t]{14}{*}{ No intervention } & Follow-up: 3 weeks \\
\hline & & IG: $n=14 ;$ CG: $n=8$ & & & TTM & & Drop outs: $n=0$ \\
\hline & & Gender: & & & & & IG: $n=0 ; C G: n=0$ \\
\hline & & Male: IG = 5 (35.7\%) & & & & & \\
\hline & & $C G=6(75 \%)$ & & \multirow{3}{*}{$\begin{array}{l}\text { Delivery mode: face-to-face } \\
\text { group sessions with manual }\end{array}$} & & & \\
\hline & & Female: IG = 9 (64.3\%) & & & & & \\
\hline & & $C G=2(25 \%)$ & & & & & $\begin{array}{l}\text { Sample analyzed: } \\
n=26\end{array}$ \\
\hline & & Mean age (years): & & \multirow{7}{*}{$\begin{array}{l}\text { Facilitators: psychology } \\
\text { students }\end{array}$} & & & IG: $n=14 ; C G: n=8$ \\
\hline & & $\mathrm{IG}=60.21(\mathrm{SD} 7.74)$ & & & & & \\
\hline & & $C G=67.75(S D$ 19.30) & & & & & \\
\hline & & Time since ABI: & & & & & \\
\hline & & $\begin{array}{l}<12 \text { months: IG: } n=2 ; \text { CG: } n \\
=1 ;\end{array}$ & \multirow[t]{3}{*}{$\begin{array}{l}\text { Physical activity specific content: Whole } \\
\text { program focused on exercise. }\end{array}$} & & & & \\
\hline & & $\begin{array}{l}1 \text { to } 5 \text { years: IG: } n=7 ; \text { CG: } n \\
=4 ;\end{array}$ & & & & & \\
\hline & & $>5$ years: IG: $n=5 ;$ CG: $n=3$ & & & & & \\
\hline Kim and Kim & \multirow[t]{11}{*}{ Stroke } & Sample size: $n=61$ & \multirow{9}{*}{$\begin{array}{l}\text { 'Lifestyle modification coaching program': } \\
\text { Aimed to modify lifestyle to prevent } \\
\text { secondary stroke, particularly through } \\
\text { reduction in physiological parameters, } \\
\text { such as blood pressure, blood lipids, and } \\
\text { body fat. Program focused on education } \\
\text { regarding stroke risk factors and } \\
\text { acknowledgement of necessity for } \\
\text { lifestyle modification, as well the setting } \\
\text { up and attainment of individual goals. }\end{array}$} & Duration: 8 weeks & \multirow{11}{*}{$\begin{array}{l}\text { None } \\
\text { specified }\end{array}$} & \multirow{11}{*}{$\begin{array}{l}\text { Control received the } 1 \times \\
\text { face-face session but no } \\
\text { ongoing telephone } \\
\text { coaching. }\end{array}$} & Follow-up: 8 weeks \\
\hline (2013, Korea & & IG: $n=32 ; C G: n=29$ & & \multirow{6}{*}{$\begin{array}{l}\text { Delivery mode: Initial session } \\
\text { was face-to-face, then } \\
\text { telephone }(1 \times \text { week for } \\
8 \text { weeks) }\end{array}$} & & & Drop outs: $\mathrm{n}=12$ \\
\hline \multirow[t]{9}{*}{$\mathrm{QRCT})$} & & Gender: & & & & & IG: $\mathrm{n}=5 ; \mathrm{CG}: \mathrm{n}=7$ \\
\hline & & Male: IG = 19 (59.4\%) & & & & & \\
\hline & & $C G=19(65.5 \%)$ & & & & & \\
\hline & & Female: IG = 13(40.6\%) & & & & & Sample analyzed: \\
\hline & & $C G=10(34.5 \%)$ & & & & & $n=61$ \\
\hline & & Mean age (years): & & \multirow[t]{4}{*}{ Facilitators: not specified } & & & IG: $n=32 ; C G: n=29$ \\
\hline & & IG: 67.41 (8.46) & & & & & \\
\hline & & CG: $66.71(9.40)$ & \multirow[b]{2}{*}{$\begin{array}{l}\text { Physical activity specific content: Participants } \\
\text { were classified according to their baseline } \\
\text { level of activity and encouraged to } \\
\text { acknowledge their current level of activity. } \\
\text { Subjects educated about optimum levels } \\
\text { of exercise to prevent stroke recurrence, } \\
\text { and assisted to set goals and keep records } \\
\text { on exercise performed. The researcher } \\
\text { checked if reasonable exercise was being } \\
\text { done, offered encouragement, and gave } \\
\text { support to identify and overcome barriers. }\end{array}$} & & & & \\
\hline & & $\begin{array}{l}\text { Median (range) time since } \\
\text { ABI (months): IG: } 24 \text { ( } 2 \text { to } \\
\text { 124)CG: } 36 \text { (2 to 188) }\end{array}$ & & & & & \\
\hline
\end{tabular}


Table 2 Summary of included studies (Continued)

\begin{tabular}{|c|c|c|c|c|c|c|c|}
\hline \multirow{12}{*}{$\begin{array}{l}\text { Sit et al. (2007, } \\
\text { Hong Kong, } \\
\text { QRCT) }\end{array}$} & \multirow[t]{12}{*}{ Stroke } & Sample size: $n=190$ & \multirow{11}{*}{$\begin{array}{l}\text { 'Community-based stroke prevention } \\
\text { program': Focus was on improving } \\
\text { knowledge about stroke, improving } \\
\text { self-monitoring of health and maintenance } \\
\text { of behavioral changes when adopting a } \\
\text { healthy lifestyle. Participants selected the } \\
\text { risk behavior on which they wanted to } \\
\text { focus, addressing them one at a time, } \\
\text { setting short-term practical goals, practicing } \\
\text { learnt skills, and implementing action plans. }\end{array}$} & \multirow{7}{*}{$\begin{array}{l}\text { Duration: } 8 \times 2 \text { h sessions } \\
\text { held } 1 / \text { week for } 8 \text { weeks. } \\
\text { Delivery mode: face-to-face } \\
\text { group sessions with } 10 \text { to } \\
12 \text { participants. }\end{array}$} & \multirow{12}{*}{$\begin{array}{l}\text { None } \\
\text { specified }\end{array}$} & \multirow{12}{*}{$\begin{array}{l}\text { Conventional medical } \\
\text { treatment and health } \\
\text { promotion pamphlets } \\
\text { on stroke and stroke } \\
\text { prevention. }\end{array}$} & \multirow{4}{*}{$\begin{array}{l}\text { Follow-up: } 1 \text { week } \\
\text { following intervention } \\
\text { and } 3 \text { months }\end{array}$} \\
\hline & & IG: $n=107 ; C G: n=83$ & & & & & \\
\hline & & Gender: & & & & & \\
\hline & & Male: IG = 55 (51.4\%) & & & & & \\
\hline & & $C G=50(60.2 \%)$ & & & & & Drop outs: $n=44$ \\
\hline & & Female: IG = 52 (48.6\%) & & & & & IG: $n=28 ; C G: n=16$ \\
\hline & & $C G=33(39.80 \%)$ & & & & & Sample analyzed: \\
\hline & & & & & & & $n=190$ \\
\hline & & Mean age (years): & & Facilitators: experienced & & & IG: $n=107 ; C G: n=83$ \\
\hline & & $\mathrm{IG}=62.83(\mathrm{SD} 10.25)$ & & & & & \\
\hline & & $C G=64.02(S D 12.03)$ & & & & & \\
\hline & & $\begin{array}{l}\text { Time since ABI: not } \\
\text { specified }\end{array}$ & $\begin{array}{l}\text { Physical activity specific content: Participants } \\
\text { were given log sheets and pedometers to } \\
\text { track goal achievement. Physical activity was } \\
\text { focused on in session 7: 'Establishing regular } \\
\text { exercise habit'. }\end{array}$ & & & & \\
\hline
\end{tabular}

IG = Intervention group; $C G=$ Control group; $T \mathrm{TM}=$ Transtheoretical Model; SCT = Social Cognitive Theory; CDSMP = Chronic Disease Self-Management Program; eHBM = expanded Health Beliefs Model. 
four of the five studies, physical activity, or exercise, was included as a subtopic within a larger program covering numerous aspects of self-management skills following acquired brain injury, such as diet modification, stress management, and medication compliance $[55,56,58,59]$. The intervention evaluated by Gill and Sullivan [57] was the only one that focused solely on exercise, with an intervention designed to boost exercise beliefs and motivation.

Three of the five studies applied theoretical models of health behavior change in developing their intervention content [55-57]. Theories utilized included Bandura's social cognitive theory (SCT) $[60,61]$, Prochaska's transtheoretical model (TTM) [62], and the expanded health beliefs model (eHBM) [63]. The remaining two studies $[58,59]$ utilized similar behavior change principles in an educational framework, with a focus on building knowledge regarding current stroke management and stroke risk factors, individual goal setting, and self-monitoring.

\section{Delivery characteristics}

The delivery characteristics of the intervention programs are outlined in Table 2. Most of the interventions were delivered during an 8- to 12-week time frame. All the interventions included at least some element of face-toface delivery; however, two studies delivered the majority of their intervention remotely via telephone $[56,58]$. The three studies that utilized only face-to-face delivery all did this via group sessions $[55,57,59]$. Standardized manuals or workbooks to assist in the delivery of the intervention were utilized in three studies [55-57]. All interventions were facilitated by health professionals, including a multidisciplinary team facilitating sessions in two of the five studies $[55,56]$. Nurses were most commonly engaged in the role of facilitator $[55,56,59]$.

\section{Outcome measures}

Each of the included studies reported on a different set of outcome measures to examine physical activity, as summarized in Table 3. Three studies measured physical activity specifically $[56,58,59]$. Damush and colleagues recorded self-reported time spent in aerobic activity each week [56]. Kim and Kim recorded weekly metabolic equivalent of task (MET) minutes by using self-reported information from a translated version of the International Physical Activity Questionnaire (IPAQ) [58]. Sit and colleagues utilized an exercise subscale modified from Lorig [64] and reported physical activity data as the proportion of the group that participated in walking exercise [59]. The remaining two studies utilized different validated questionnaires regarding physical activity, including the Health Promoting Lifestyle Profile - II (HPLP-II) Physical Activity subscale [55], the Self-Rated
Abilities for Health Practices (SRAHP) Exercise subscale [55], and the Cerebrovascular Attitudes and Beliefs Scale Revised (CABS-R) Exercise subscale [57].

In addition to these specific physical activity measures, a wide variety of secondary outcome measures were used by the authors to examine other factors associated with self-management of acquired brain injury, such as self-efficacy for communicating with physicians [56] or smoking and alcohol behavior [58]. We extracted data only from those measures that were aligned with the secondary outcome measures outlined in our protocol [45]. These results are summarized in Table 3. No studies employed outcome measures to examine participant satisfaction or program cost-effectiveness. Adverse events were also not reported in any of the studies included in this review.

\section{Risk of bias of included studies}

Risk of bias for each study is summarized in Figure 2, with a summary of each risk of bias item detailed in Figure 3. Overall, risk of bias was generally high across all parameters. Four of the five studies are at high risk of selection bias with only one study providing clear information regarding adequate random sequence generation and allocation concealment [55]. Blinding of facilitators is impossible in these types of studies and blinding of participants is also challenging, but none of the included studies demonstrated clarity regarding blinding of participants [56-59]. This is particularly pertinent in these studies where data was collected through self-report measures. As a result, all studies were considered to be at high risk of performance bias. Three studies were considered to be at high risk of reporting bias with data not fully presented and/or difficult to analyze [55,56,59]. Other potential sources of bias arose due to differences in groups at baseline regarding physical activity measures, issues regarding the delivery and monitoring of control interventions, and the use of post hoc statistical analysis techniques $[55,56,58]$.

\section{Effects of interventions \\ Efficacy in improving physical activity}

A summary of results is displayed in Table 3. As stated previously, a meta-analysis was not possible due to the significant variability in outcome measures utilized in each study. Therefore, a pooled estimate of efficacy cannot be established at this stage. However, in one study of stroke survivors, there is evidence that an 8-week lifestyle modification coaching program that included physical activity specific content relative to baseline levels of physical activity was effective in increasing the amount of physical activity as measured in weekly MET minutes with a median increase of 610.5 weekly MET minutes (range: $-2,628$ to 3,696 ) in the intervention group and 


\section{Study}

Brenner et al. [55]

Damush et al. [8]

Gill and Sullivan [57]

Kim and Kim [58]

\section{Measure used}

Physical activity

measure: HPLP-II Physical Activity Subscale

SRAHP Physical Activity \& Exercise domain

Other measures: Participation Assessment with Recombined Tools-Objective (PART-O)

Diener Satisfaction with Life Scale

Physical activity measure: Self-reported time spent in aerobic activity (min/week)

Other measures: Stroke-Specific Health-Related Quality of Life (SSQOL)

Physical activity measure:

Cerebrovascular Attitudes and Beliefs

Scale-Revised (CABS-R) Exercise subscale

SOEQ (stages of change, 1 item)

Physical activity measure: Physical activity: MET minutes/week

Other measures: General Self-Efficacy Scale
Results

Raw data: No raw data reported

Group comparisons: Data reported as time-by-treatment interaction $(P)$ - no significant differences between the IG and CG in regard to HPLP-II (Physical Activity) $(P=0.2375)$ or SRAHP (Exercise) $(P=0.3661)$.

Both these values reached significance $(P=0.0216$ and $P=0.0001$ respectively): however, the authors state differences are due to time, not treatment.

Raw data [1] :

IG: Baseline $=78.5 \mathrm{~min} /$ week; 3 months $=$ mean increase of $47.6 \mathrm{~min} /$ week CG: Baseline $=107.4 \mathrm{~min} /$ week; 3 months $=$ mean decrease of $3 \mathrm{~min} /$ week.

Between-group comparison: 3 months: $t_{(51)}=1.18, P \leq 0.13$, effect size $=-0.43 ; 6$ months: $P \leq 0.50$, effect size $=-0.19$

Not all data supplied. At baseline, the IG had significantly lower (worse) scores for several SSQOL scales including mobility, thinking, energy, and work, as well as the total overall score. For both the subscales of Family Roles and Social Roles, the IG improved at 3 months, while the CG declined with differences between the groups reaching significance ( $P \leq 0.01$ and $P \leq 0.06$, respectively).

Raw data: Mean (SD) self-ratings.

Barriers: IG: $\mathrm{T} 1=2.19(0.76), \mathrm{T} 2=2.35(0.67) ; \mathrm{CG}: \mathrm{T} 1=2.22(0.49), \mathrm{T} 2=2.27(0.74)$ Benefits: IG: $\mathrm{T} 1=3.90(0.73), \mathrm{T} 2=3.94(0.46) ; \mathrm{CG}: \mathrm{T} 1=3.59(0.67), \mathrm{T} 2=3.53(0.60)$ Susceptibility: IG: $\mathrm{T} 1=3.62(0.86), \mathrm{T} 2=3.69(0.60) ; \mathrm{CG}: \mathrm{T} 1=2.42(0.94), \mathrm{T} 2=2.92(0.61)$. Seriousness: IG: $\mathrm{T} 1=4.18(1.05), \mathrm{T} 2=4.26(0.76) ; \mathrm{CG}: \mathrm{T} 1=3.71(1.38), \mathrm{T} 2=3.50(1.41)$ Self-efficacy: IG: $\mathrm{T} 1=3.31(0.90), \mathrm{T} 2=3.77(0.53)$; CG: $\mathrm{T} 1=3.13(1.09), \mathrm{T} 2=3.25(1.00)$ Subjective norms: IG: $\mathrm{T} 1=4.27(0.53), \mathrm{T} 2=4.08(0.53) ; \mathrm{CG}: \mathrm{T} 1=4.06(0.18), \mathrm{T} 2=4.06(0.18)$ Within-group comparison: IG showed a significant increase in self-efficacy from baseline to follow up $(F(1,11)=7.33 ; P=0.02)$.

Between-group comparison: IG reported significantly higher perceptions of susceptibility than CG at both time points (baseline $P=0.007$ and 3 weeks $P=0.010)$. No other differences were found.

The IG had a small movement of $14.3 \%(n=2)$ from the preparation stage to the active stage at 3 weeks which was not seen in the CG on SOEQ categorical data. No other changes were found.

Raw data: Median (range)

IG: Baseline $=462.0$ (0.0 to 3,942.0), 8 weeks $=1,365.5$ (132.0 to 4,158.0)

CG: Baseline $=984.0(0.0$ to 6,906.6), 8 weeks $=990.0$ (0.0 to 25,638.0)

Within-group comparison: IG showed significant increase in weekly MET minutes at 8 weeks with a difference in median between baseline and 8 weeks to be 601.5 MET min/week (range -2,628.0 to 3696.0; $T=149 ; P=0.001$ ); CG showed a 
Between-group comparison: Difference in change over 8 weeks was significantly different between groups in favor of IG ( $T=692.50 ; P=0.002)$.

No significant differences found within groups or between groups in general self-efficacy.

Sit et al. [59] Physical activity measure: Participation in

Raw data: Percentages reported; $\mathrm{T} 0=$ baseline, $\mathrm{T} 1=$ postone week, $\mathrm{T} 2=3$ months walking exercise

IG: $\mathrm{T} 0=78.9 \%, \mathrm{~T} 1=78.9 \%, \mathrm{~T} 2=77.1 \%$

CG: T0 $=72.3 \%, \mathrm{~T} 1=63.9 \%, \mathrm{~T} 2=55.4 \%$

Within-group comparison: At 3 months: $\mathrm{IG} \mathrm{Q}=0.051 ; \mathrm{P}=0.975, \mathrm{CG} \mathrm{Q}=7.697$; $P=0.021$

Between-group comparison: At 3 months, there was a significant difference between groups in favor of the IG $(P<0.001)$

Data from Damush et al. (2011) included 6 month data that reported a mean increase in the IG of $24.4 \mathrm{~min} /$ week and a mean increase in the CG of 4 min/week, with a between-group comparison of $t_{(52)}=-0.69$, $P \leq 0.50$, effect size $=-0.19$; however, this data was not reported in this table as it was unclear as to whether these increases were from baseline or from 3 months. 


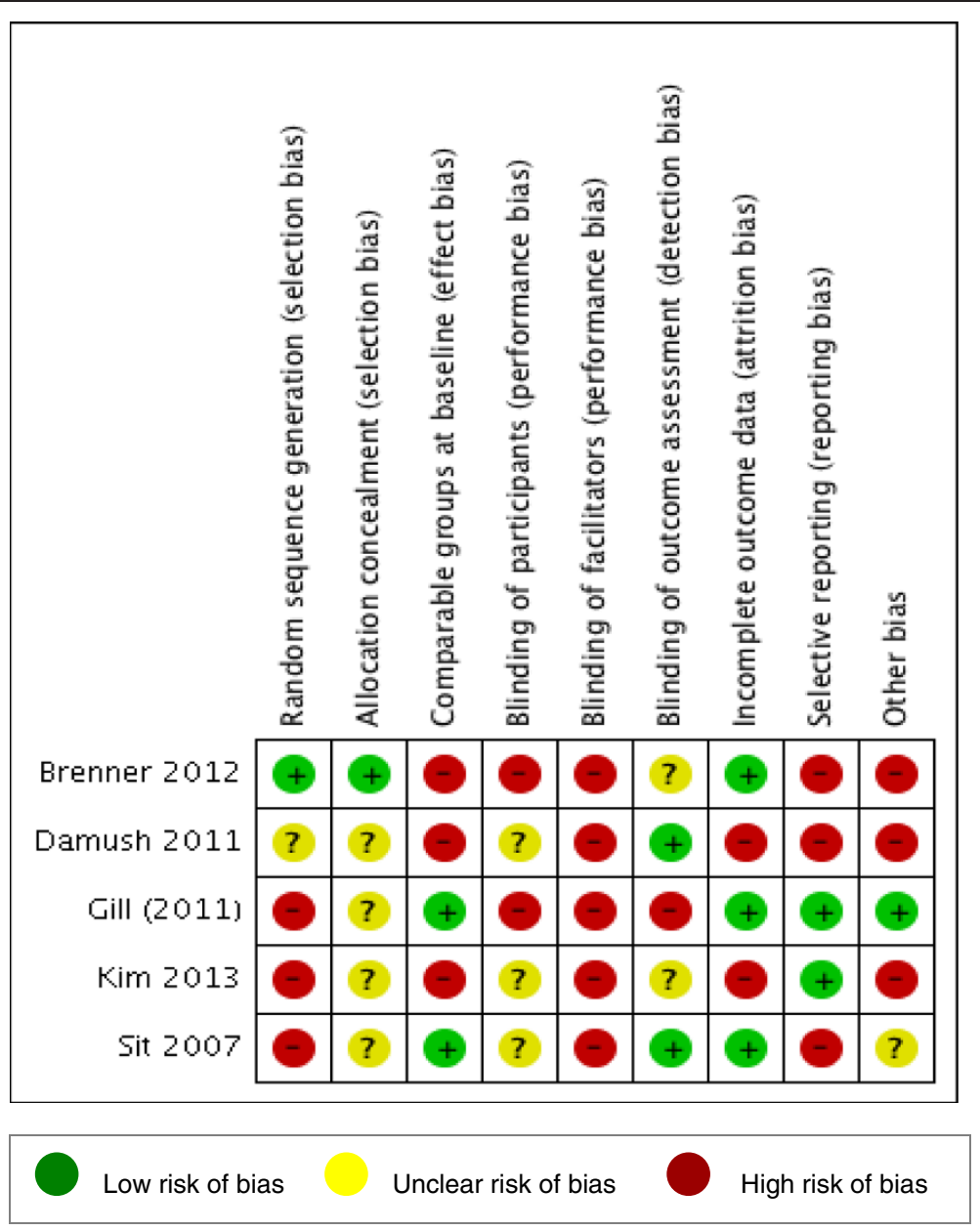

Figure 2 Risk of bias summary - review authors' judgements about each risk of bias item for each included study.

133.0 (range: -4976 to 25,638 ) in the control group with a significant between-group difference $(T=692.50 ; P=$ 0.002) [58]. An 8-week community-based stroke prevention program with a focus on increasing walking for exercise as one component of a secondary risk prevention program resulted in maintenance of the proportion of individuals that were participating in walking for exercise in the intervention group at 3 months (non-significant decline of $1.8 \% ; P=0.975$ ), while the control group saw a significant decline of $16.9 \% ; P=0.021$ ), resulting

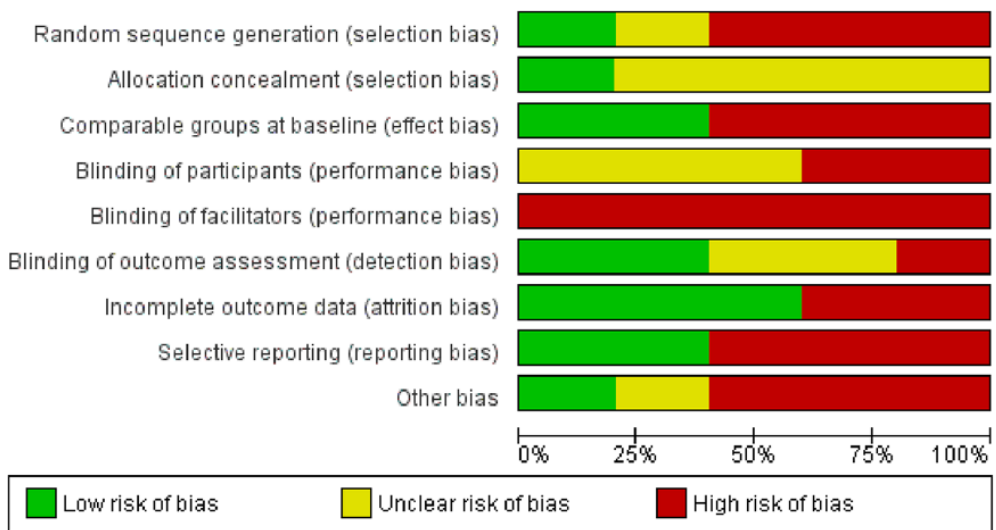

Figure 3 Risk of bias graph - review authors' judgements about each risk of bias item presented as percentages across all included studies. 
in a significant between-group difference at 3 months $(P<0.001)$ [59]. The study by Damush and colleagues [56] reported limited data about physical activity outcomes from their 'Stroke Self-management Program'. We were unable to obtain further data for analysis from the study's authors. From the published results, there does appear to be an average increase of $47.6 \mathrm{~min} /$ week in self-reported time spent doing aerobic activity at 3 months in the intervention group and an average decline in the control group of $3 \mathrm{~min} /$ week [56]. However, these results should be interpreted with caution given the control group was more active than the intervention group at baseline (107.8 vs. $78.9 \mathrm{~min} /$ week on average, respectively). Gill and Sullivan's 'Stay Active and Stop Stroke' program demonstrated limited benefits from this short intervention on the CABS-R Exercise subscale [57]. A significant increase in self-efficacy for exercise was seen in the intervention group at follow-up $(F(1,11)=$ 7.33; $P=0.02)$; however, this did not result in a significant difference between groups. In TBI, Brenner and colleagues reported limited data from the physical activity subscales HPLP-II Physical Activity Subscale and SRAHP Physical Activity and Exercise domain. Further data were unable to be obtained from the authors. The reported program outcomes showed no significant betweengroup differences [55].

\section{Efficacy and acceptability of remote delivery}

No study in this review utilized remote delivery of a selfmanagement program in isolation from face-to-face delivery. Remote delivery via telephone was the predominant form of delivery in two studies [56,58]. Although efficacy of remote delivery in isolation cannot be fully established at this stage, current evidence does support the inclusion of remote delivery modes in self-management programs for individuals following stroke. Acceptability of delivery mode was not formerly assessed in either study. Attrition rates were low in both studies; however, reasons for attrition were not reported.

\section{Program features associated with optimal clinical outcomes and client satisfaction}

Due to the heterogeneity of outcome measures, as well as program content and delivery characteristics, a comparison of studies in order to determine features associated with best clinical outcomes is difficult. In addition, there was no analysis of client satisfaction in any of the studies included in this review. The amount of specific physical activity-related program content was not able to be clearly established in four of the five studies included in this review due to physical activity being a subtopic of a larger self-management program $[55,56,58,59]$. It was also difficult to establish the depth to which content was covered and the extent to which skills were taught and practiced. Education and goal setting were employed in all interventions and did not differentiate studies that obtained more positive results from those that demonstrated less efficacy of intervention. Sit and colleagues [59] were the only authors to implement the concept of individual preferences for both the choice of the risk behavior they wanted to focus on each week, as well as individual preferences for exercise pattern, duration, and pace. This was also the only study to focus on the formation of healthy habits as a part of their behavioral change intervention. Positive intervention results were also seen with the use of planning and scheduling $[56,59]$ and coping strategies [56,58], while mixed success was seen with the implementation of barrier identification skills [55,57,58], problem solving [55-57], and self-monitoring [57-59].

\section{Discussion}

This is the first review, to the authors' knowledge, that has attempted to examine the clinical efficacy of selfmanagement programs aimed at improving physical activity levels following ABI. This is an important contemporary issue in health care, and there is a growing body of literature in this area. However, there were a scant number of studies that met our stringent eligibility criteria. Many studies were excluded because they were not randomized or quasi-randomized controlled trials or because they did not utilize a self-management approach or examine physical activity specifically. An alternative approach to a future review in this field would be to include non-randomized studies and applying the GRADE approach to the examination of the quality of the evidence [43]. This may allow for more thorough examination of pragmatic trials conducted in this area.

The studies included in this review had a high risk of potential bias on many parameters. In part, this may be because some were smaller proof of concept studies, as is common in an emerging field. Nonetheless, the high risk of bias does limit interpretation of efficacy for the interventions investigated. With this taken into consideration, the results do show promising trends towards physical activity being enhanced through participation in a self-management program for individuals following stroke. This trend is not currently supported in TBI where the amount of research is even less, as highlighted by Pawlowski and colleagues. Their review of the status of physical activity research for individuals with TBI found only $6 \%(n=4 / 63)$ of studies focused on the evaluation of behavior change intervention, and only $5 \%$ $(n=3 / 63)$ examined dissemination of health promotion programs [18]. More rigorous research is clearly needed in order to establish the efficacy and acceptability of self-management programs in improving physical activity levels for community-dwelling adults with ABI. 
It was difficult to synthesize the results of the different self-management programs covered in this review, primarily because of variation in program content and delivery characteristics. Four studies examined selfmanagement programs in which physical activity was only a small component of the overall program, rather than the main focus $[55,56,58,59]$, making it difficult to establish the proportion and duration of the program that was focused on the acquisition of physical activity specific self-management skills in these studies. In the fifth study, although the focus of the program was specifically on physical activity [57], it was significantly shorter than the others at $1 \mathrm{~h}$ /week for 3 weeks in duration. In summary, while limited, the available evidence examined in this review indicates benefits in physical activity for stroke survivors of programs consisting of 6 to 8 sessions over 8 to 12 weeks. The evidence indicates that changing behavior related to physical activity is difficult in this population, particularly achieving sustained changes over time [65]. It is possible that too a short program does not allow for the establishment of skills needed for long-term behavior change to occur.

This review has demonstrated that self-management programs for stroke survivors that use a holistic, multifaceted approach offer some benefits in improving physical activity $[56,58,59]$. However, the concept of a selfmanagement program that focuses on one risk factor, such as physical activity, also warrants further investigation. Sit and colleagues demonstrated positive results with a program that involved participants choosing the risk behavior on which they wanted to focus each week [59]. Such a focus on one self-selected risk factor has also been shown to have good effect on long-term physical activity levels in self-management programs with other populations, such as those with cardiovascular disease [66]. People with ABI often have complex disabilities and face multiple barriers and challenges in the self-management of physical activity. Therefore, a program that specifically targets physical activity may potentially be more effective in establishing long-term behavior change than a program that focuses on simultaneously changing numerous risk factors. Given the significance of physical inactivity to the global burden of chronic disease, this proposal warrants further investigation.

The professional background of the facilitators used in the programs reviewed here is also an issue of interest. The types of health professionals varied greatly between studies. Nurses were most commonly engaged as facilitators, with three of the five studies using at least one nurse in their facilitation team $[55,56,58]$. The experience and skills of the facilitators to help people increase physical activity following $\mathrm{ABI}$ is an important consideration in an analysis of efficacy of self-management programs to increase physical activity. However, this information was not reported in any of the included studies. People with $\mathrm{ABI}$ face many unique barriers to engaging in physical activity, such as mobility impairments, pain, fear, and limitations regarding access [4-8]. The experience of the facilitators in regard to changing physical activity behavior is an important factor to consider in any study that aims to increase physical activity levels of individuals with ABI.

The overall conclusions that can currently be drawn regarding efficacy of self-management programs for improving physical activity following ABI are limited. This is primarily because of the heterogeneity of methodological features such as the outcome measures used and how physical activity was operationalized. No study collected objective measures of physical activity such as from accelerometers or other devices. Although Sit and colleagues did have participants log data from pedometers for their own self-monitoring, these data were not reported in the study [59]. All five studies employed different self-report assessments of physical activity, each based on a different construct or aspect of physical activity. For example, one study measured minutes per week spent in aerobic activity [56] while another study examined attitudes and beliefs regarding exercise [57]. Additionally, in three of the five studies, the physical activity outcome was not the primary outcome [56,58,59]. In another study, the physical activity measure was a subscale of the primary outcome measure [55], which limits the power of the study to make conclusions about physical activity. Boger and colleagues have stated that the use of outcome measures which are related, indirect, or proxy indicators of self-management and that have questionable reliability and validity, contributes to an inability to sensitively evaluate the effectiveness of stroke self-management interventions [47]. Thus, in future research, employing objective measures of physical activity along with validated self-report measures that can capture participation in a broad range of physical activities is important and will enable a more rigorous investigation of the efficacy of self-management interventions aimed at in improving physical activity levels.

An additional limitation of this review may come from the common diversity seen in an ABI population. Studies examining both individuals with stroke and those with TBI were included in this review. There are obvious differences between these populations, for example, etiology and average age. There was also limited information regarding the specific mobility or physical activity status of the included participants. This may impact on both the examination of overall efficacy and the ability to translate these results into practice. However, all the participants were community-dwelling adults with the cognitive and communicative ability to participate in a self-management program. 
A second objective of this review was to assess the effectiveness and acceptability of self-management programs delivered remotely, that is, via telephone, computer, posted workbooks, and the Internet. The evidence on this question is even more limited and preliminary. Two of the five studies utilized one form of remote delivery, specifically telephone, with both studies showing positive findings in terms of increasing physical activity $[56,58]$. As outlined above, ABI survivors face many barriers to participate in physical activity and difficulties in accessing self-management programs due to mobility impairments, transport limitations, lack of specialist resources, and cost [4-8]. Remote delivery of interventions may assist in overcoming some of these barriers and access issues [33]; however, research into this area is limited. Dishman and Buckworth conducted a metaanalysis of 127 studies examining the efficacy of interventions delivered via differing modes for increasing physical activity in community, worksite, school, home, and health-care settings. They reported that physical activity programs utilizing mediated delivery methods, such as the Internet, are more effective than those using just face-to-face methods [65]. Although this differs from the findings of Conn et al. [67], who found face-toface delivery produced superior outcomes in healthy adults, a recent Cochrane review by Foster et al. [41] has shown consistent evidence to support the effectiveness of remote and web-based interventions for promoting physical activity in generally healthy community-dwelling adult populations. There are also promising results from a number of non-randomized stroke-specific studies utilizing telehealth interventions [68-71], and it is important to note that the acceptability of remote interventions may be examined in more detail in these earlier stage research studies. Further research into the efficacy of remote delivery of self-management programs for ABI survivors, specifically aimed at improving physical activity levels, is therefore warranted given the importance of physical activity and the difficulties of people with $\mathrm{ABI}$ report in accessing self-management programs.

This review also aimed to establish which features of self-management interventions were associated with the optimal clinical outcomes and client satisfaction for participants. Although specific content related to physical activity was difficult to quantify, a number of common features were seen across the five studies. For example, education and goal setting were features of all the intervention programs included in this review. This is important because improving health literacy through health education programs helps build the capacity of individuals to seek, access, comprehend, and effectively utilize health information and services [22,72,73]. Goal setting, when combined with improved health literacy, does appear to positively influence patients' perceptions of self-care ability and engagement in rehabilitation following stroke [54]. However, education and goal setting did not differentiate a positive study from one that was less effective. It is difficult to establish whether programs were developed in a way that effectively targeted the level of health literacy of the users to allow for behavior change. Brenner and colleagues report on performing a pilot study of the program used in their study on eight participants with no resulting change to the materials [55], while Damush and colleagues report on developing their program with input from key stakeholders, including veterans with stroke [56]. Other authors report on building programs based on findings from local studies and focus groups [57,59]; however, although this may assist with content development, it does not guarantee that materials were targeted at the correct level of health literacy for users. The complexities of the manner in which these elements were delivered cannot be differentiated with the current evidence. Other program components were inconsistent between studies. These included self-monitoring, teaching coping strategies, planning and scheduling, barrier identification, problem solving, and habit formation.

Three of the five studies based their interventions on recognized psychological theories of behavior change, namely, the transtheoretical model, social cognitive model, and expanded health beliefs model [55-57]. Sit et al. did not specify a particular model of behavior change on which their program is based but do discuss the importance of modification of lifestyle habits as a component of behavioral change [59]. Kim and Kim also did not specify any theoretical basis to their interventions but utilized an educational framework with similar behavior change principles to the other studies examined [58]. Utilizing both psychological science and best educational practices can optimize the impact of self-management programs [22], and physical activity programs based on the principles of behavior modification have shown to be more effective than those based on cognitive modification [65,67]. A review of more than 550 pieces of high-quality research by de Silva [29] suggests that it is worthwhile to support self-management of individuals with chronic health conditions, particularly when there is a focus on behavior change and increasing selfefficacy, through approaches such as motivational interviewing and coaching with active goal setting. Future self-management programs aiming to increase physical activity following ABI should continue to adhere to these principles.

\section{Conclusions}

The field of self-management of chronic health conditions is rapidly growing, and successes have been demonstrated 
in a range of conditions, such as depression and chronic pain. The application of this approach for individuals with $\mathrm{ABI}$ is emerging. To date, there are a limited number of trials that have specifically investigated the efficacy of self-management to improve physical activity in this population. However, the risk of bias of these studies is generally high, and analysis is limited by heterogeneity in study interventions, methodology, measures, and diversity of the $A B I$ population. Based on the results of this review, the efficacy of self-management programs in increasing physical activity levels in communitydwelling adults following ABI is still unknown. Moreover, the efficacy and acceptability of remotely delivered self-management programs for increasing physical activity levels after $\mathrm{ABI}$ is also unknown.

Further research into physical activity following selfmanagement interventions for community-dwelling adults with $\mathrm{ABI}$ is required in order to properly establish efficacy and implications for practice. This research should be designed, undertaken, and reported on in a manner that reduces the potential for bias and allows for establishment of efficacy. Remote delivery methods also warrant further research given the potential they offer in regard to improving access, overcoming barriers, and changing health behaviors.

\section{Additional file}

Additional file 1: MEDLINE search strategy. Final search strategy used in MEDLINE.

\begin{abstract}
Abbreviations
ABI: Acquired brain injury; CABS-R: Cerebrovascular attitudes and beliefs scale - revised; CENTRAL: Cochrane central register of controlled trials; eHBM: expanded health beliefs model; FASD: Fetal alcohol spectrum disorder; HPLP-II: Health promoting lifestyle practices - Il; IPAQ: International physical activity questionnaire; MET: Metabolic equivalent of task; PRISMA: Preferred reporting items for systematic reviews and meta-analyses; SCI-EXPANDED: Science citation index expanded; SCT: Social cognitive theory; SRAHP: Self-rated abilities for health practices; TBI: Traumatic brain injury; TIA: Transient ischaemic attack; TTM: Transtheoretical model; WHO: World health organization.
\end{abstract}

\section{Competing interests}

The authors declare that they have no competing interests.

\section{Authors' contributions}

TMJ participated in the conception and design, data collection, analysis and interpretation, manuscript writing, and final approval of the manuscript. CMD participated in the conception and design, data collection, analysis and interpretation, manuscript writing and critical revision, and final approval of the manuscript. JMH participated in the conception and design, data analysis and interpretation, manuscript writing and critical revision, and final approval of the manuscript. BFD participated in the conception and design, data analysis and interpretation, critical revision of the manuscript, and final approval of the manuscript. NT participated in the conception and design, interpretation of the data, critical revision of the manuscript, and final approval of the manuscript. All authors read and approved the final manuscript.

\section{Acknowledgements}

The authors express their gratitude to the excellent assistance of Macquarie University librarian Ms. Mary Simon with the development of the database searches and data management, and Ms Sun Lee who provided independent translation of Korean manuscripts to English. TMJ is supported by a Macquarie University Research Excellence Scholarship. BFD is supported by a National Health and Medical Research Council (NHMRC) Australian Public Health Fellowship.

\section{Author details}

${ }^{1}$ Department of Health Professions, Macquarie University, Ground Floor, 75 Talavera Rd, Sydney, NSW 2109, Australia. ²Department of Psychology, Centre for Emotional Health, Building C3A, Level 7, Macquarie University, Sydney 2109, Australia. ${ }^{3}$ Centre for Physical Health, Macquarie University, Ground Floor, 75 Talavera Rd, Sydney 2109, Australia.

Received: 15 December 2014 Accepted: 31 March 2015

Published online: 19 April 2015

\section{References}

1. O'Rance L. Disability in Australia: acquired brain injury. Canberra: AlHW; 2007. p. 28.

2. Thrift AG, Cadilhac DA, Thayabaranathan T, Howard G, Howard VJ, Rothwell PM, et al. Global stroke statistics. Int J Stroke. 2014;9(1):6-18.

3. World Health Organization. Neurological disorders: public health challenges. Geneva: WHO; 2006.

4. Mathers CD, Fat DM, Boerma J. The global burden of disease: 2004 update. Geneva: WHO; 2008.

5. Driver S, Ede A, Dodd Z, Stevens L, Warren AM. What barriers to physical activity do individuals with a recent brain injury face? Disabil Health J. 2012;5(2):117-25.

6. Nicholson S, Sniehotta FF, van Wijck F, Greig CA, Johnston M, McMurdo MET, et al. A systematic review of perceived barriers and motivators to physical activity after stroke. Int J Stroke. 2013;8(5):357-64.

7. Rimmer JH, Wang E, Smith D. Barriers associated with exercise and community access for individuals with stroke. J Rehabil Res Dev. 2008;45(2):315-22.

8. Damush TM, Plue L, Bakas T, Schmid A, Williams LS. Barriers and facilitators to exercise among stroke survivors. Rehab Nursing. 2007;32(6):253-62.

9. Jones TM, Dean CM, Hush JM, Dear BF, Titov N. Is the concept of an internet-based self-management program to increase physical activity acceptable to community-dwelling stroke survivors, 25th Annual Scientific Meeting of the Stroke Society of Australasia. Int J Stroke. 2014;9:35. Hamilton Island, Queensland, Australia.

10. Ada $L$, Dean $C M$, Lindley R. Randomized trial of treadmill training to improve walking in community-dwelling people after stroke: the AMBULATE trial. Int J Stroke. 2013;8(6):436-44.

11. Mudge SBPASNS. Circuit-based rehabilitation improves gait endurance but not usual walking activity in chronic stroke: a randomized controlled trial. Arch Phys Med Rehabil. 2009;90(12):1989-96.

12. States RA, Pappas E, Salem Y. Overground physical therapy gait training for chronic stroke patients with mobility deficits. Cochrane Database Syst Rev. 2009;3:CD006075.

13. Morris JH, Macgillivray S, McFarlane S. Interventions to promote long-term participation in physical activity after stroke: a systematic review of the literature. Arch Phys Med Rehabil. 2014;95(5):956-67.

14. Moore SA, Hallsworth K, Plötz T, Ford GA, Rochester L, Trenell MI. Physical activity, sedentary behaviour and metabolic control following stroke: a cross-sectional and longitudinal study. PLOS ONE. 2013;8(1), e55263.

15. Driver S, Ede A. Impact of physical activity on mood after TBI. Brain Injury. 2009;23(3):203-12.

16. Grealy MA, Johnson DA, Rushton SK. Improving cognitive function after brain injury: the use of exercise and virtual reality. Arch Phys Med Rehabil. 1999:80(6):661-7.

17. Mathers C, Stevens G, Mascarenhas M. Global health risks: mortality and burden of disease attributable to selected major risks. Geneva: WHO; 2009.

18. Pawlowski J, Dixon-lbarra A, Driver S, Driver S. Review of the status of physical activity research for individuals with traumatic brain injury. Arch Phys Med Rehabil. 2013;94(6):1184-9.

19. Cleveland S, Driver S, Swank C, Macklin S: Classifying physical activity research following stroke using the behavioral epidemiologic framework. Top Stroke Rehabil 2015, (Online ahead of print) doi:10.1179/1074935714Z.0000000043. 
20. World Health Organization. Preventing chronic diseases: a vital investment. Geneva: WHO; 2005.

21. World Health Organization. Global recommendations on physical activity for health. Geneva: WHO; 2010.

22. Glasgow NJ, Jeon Y-H, Kraus SG, Pearce-Brown CL. Chronic disease self-management support: the way forward for Australia. Med J Aust. 2008;189(10):S14-16.

23. Lee CD, Folsom AR, Blair SN. Physical activity and stroke risk: a meta-analysis. Stroke. 2003;34(10):2475-81.

24. Lorig KR, Holman $H$. Self-management education: history, definition, outcomes, and mechanisms. Ann Behav Med. 2003;26(1):1-7.

25. Barker A, Brand C, Haines T, Hill K, Brauer S, Jolley D, et al. The 6-PACK programme to decrease fall-related injuries in acute hospitals: protocol for a cluster randomised controlled trial. Injury Prev. 2011;17(4):e5.

26. Marks R, Allegrante JP, Lorig K. A review and synthesis of research evidence for self-efficacy-enhancing interventions for reducing chronic disability: implications for health education practice (part I). Health Promot Pract. 2005;6(1):37-43.

27. Marks R, Allegrante JP, Lorig K. A review and synthesis of research evidence for self-efficacy-enhancing interventions for reducing chronic disability: implications for health education practice (part II). Health Promot Pract. 2005;6(2):148-56.

28. Barlow J, Wright C, Sheasby J, Turner A, Hainsworth J. Self-management approaches for people with chronic conditions: a review. Patient Educ Counsel. 2002;48(2):177-87.

29. de Silva D. Evidence: helping people help themselves. London: Health Foundation; 2011.

30. Cadilhac DA, Hoffmann S, Kilkenny M, Lindley R, Lalor E, Osborne RH, et al. A phase II multicentered, single-blind, randomized, controlled trial of the stroke self-management program. Stroke. 2011;42(6):1673-9.

31. Jones F, Riazi A. Self-efficacy and self-management after stroke: a systematic review. Disabil Rehabil. 2011;33(10):797-810.

32. National Stroke Foundation. In: Foundation NS, editor. National stroke audit - rehabilitation services report 2012. Melbourne, Australia: National Stroke Foundation; 2012

33. Lorig K, Ritter PL, Plant K, Laurent DD, Kelly P, Rowe S. The South Australia health chronic disease self-management Internet trial. Health Educ Behav. 2013:40(1):67-77.

34. Dear BF, Titov N, Nicholson Perry K, Johnston L, et al. The pain course: a randomised controlled trial of clinician-guided Internet-delivered cognitive behaviour therapy program for managing chronic pain and emotional wellbeing. Pain. 2013;154(6):942-50.

35. Titov N, Andrews G, Johnston L, Robinson E, Spence J. Transdiagnostic Internet treatment for anxiety disorders: a randomized controlled trial. Behav Res Ther. 2010;48(9):890-9.

36. Titov N, Dear BF, Johnston L, Lorian C, Zou J, Wootton B, et al. Improving adherence and clinical outcomes in self-guided internet treatment for anxiety and depression: randomised controlled trial. PLOS ONE. 2013;8(7), e62873.

37. Titov N, Dear BF, Johnston L, McEvoy PM, Wootton B, Terides MD, et al. Improving adherence and clinical outcomes in self-guided Internet treatment for anxiety and depression: a 12-month follow-up of a randomised controlled trial. PLOS ONE. 2014;9(2), e89591.

38. Spence J, Titov N, Dear BF, Johnston L, Solley K, Lorian C, et al. Randomized controlled trial of Internet-delivered cognitive behavioral therapy for posttraumatic stress disorder. Depress Anxiety. 2011;28(7):541-50.

39. Lorig KR, Ritter PL, Dost A, Plant K, Laurent DD, McNeil I. The expert patients programme online, a 1-year study of an Internet-based self-management programme for people with long-term conditions. Chronic Illness. 2008;4(4):247-56.

40. Maher CA, Williams MT, Olds T, Lane AE. An internet-based physical activity intervention for adolescents with cerebral palsy: a randomized controlled trial. Develop Med Child Neurol. 2010;52(5):448-55.

41. Foster C, Richards J, Thorogood M, Hillsdon M. Remote and web 2.0 interventions for promoting physical activity. Cochrane Database Syst Rev. The Cochrane Collaboration. 2013; Issue 9. Art. No.: CD010395. doi:10.1002/ 14651858.CD010395.pub2.

42. Liberati A, Altman DG, Tetzlaff J, Mulrow C, Gøtzsche PC, loannidis JP, et al. The PRISMA statement for reporting systematic reviews and meta-analyses of studies that evaluate health care interventions: explanation and elaboration. Ann Intern Med. 2009;151(4):W-65-94.
43. Higgins J, S G: Cochrane handbook for systematic reviews of interventions version 5.1.0 [updated March 2011]. The Cochrane Collaboration; 2011.

44. PROSPERO International prospective register of systematic reviews. [http://www.crd.york.ac.uk/prospero/display_record.asp?ID=CRD42013006748\#. UrIPRPQW2a8]

45. Jones TM, Hush JM, Dear BF, Titov N, Dean CM. The efficacy of self-management programmes for increasing physical activity in community-dwelling adults with acquired brain injury (ABI): a systematic review. Sys Rev. 2014;3(1):39.

46. Higgins JP, Altman DG, Gøtzsche PC, Jüni P, Moher D, Oxman AD, et al. The Cochrane Collaboration's tool for assessing risk of bias in randomised trials. BMJ. 2011;343:d5928.

47. Boger EJ, Demain S, Latter S. Self-management: a systematic review of outcome measures adopted in self-management interventions for stroke. Disabil Rehabil. 2013;35(17):1415-28.

48. Bowen A, Knapp P, Gillespie D, Nicolson DJ, Vail A. Non-pharmacological interventions for perceptual disorders following stroke and other adult-acquired, non-progressive brain injury. Cochrane Database Syst Rev. 2011:4, CD007039.

49. Brogardh C, Lexell J. Effects of cardiorespiratory fitness and muscle-resistance training after stroke. PM and R. 2012:4(11):901-7.

50. Hailey D, Roine R, Ohinmaa A, Dennett L. Evidence of benefit from telerehabilitation in routine care: a systematic review. J Telemed Telecare. 2011;17(6):281-7.

51. Mehta S, Pereira S, Janzen S, Mclntyre A, McClure A, Teasell RW. Effectiveness of psychological interventions in chronic stage of stroke: a systematic review. Top Stroke Rehabil. 2012;19(6):536-44.

52. Smith J, Forster A, Young J. Cochrane review: information provision for stroke patients and their caregivers. Clin Rehabil. 2009;23(3):195-206.

53. Stuifbergen AK, Morris M, Jung JH, Pierini D, Morgan S. Benefits of wellness interventions for persons with chronic and disabling conditions: a review of the evidence. Disabil Health J. 2010;3(3):133-45.

54. Sugavanam T, Mead G, Bulley C, Donaghy M, van Wijck F. The effects and experiences of goal setting in stroke rehabilitation - a systematic review. Disabil Rehab. 2013;35(3):177-90.

55. Brenner LA, Braden CA, Bates M, Chase T, Hancock C, Harrison-Felix C, et al. $A$ health and wellness intervention for those with moderate to severe traumatic brain injury: a randomized controlled trial. J Head Trauma Rehabil. 2012;27(6):E57-68.

56. Damush TM, Ofner S, Yu Z, Plue L, Nicholas G, Williams LS. Implementation of a stroke self-management program: a randomized controlled pilot study of veterans with stroke. Transl Behav Med. 2011;1(4):561-72.

57. Gill L, Sullivan KA. Boosting exercise beliefs and motivation through a psychological intervention designed for poststroke populations. Top Stroke Rehabil. 2011;18(5):470-80.

58. Kim H, Kim O. The lifestyle modification coaching program for secondary stroke prevention. Journal Korean acad. 2013:43(3):331-40.

59. Sit JW, Yip WY, Ko SK, Gun AP, Lee JS. A quasi-experimental study on a community-based stroke prevention programme for clients with minor stroke. J Clin Nurs. 2007;16(2):272-81.

60. Bandura A. Health promotion by social cognitive means. Health Educ Behav. 2004;31(2):143-64.

61. Bandura A. Self-efficacy: toward a unifying theory of behavioral change. Psychol Rev. 1977;84(2):191-215.

62. Prochaska JO, Velicer WF. The transtheoretical model of health behavior change. Am J Health Prom. 1997;12(1):38-48.

63. Sullivan KA, White KM, Young RM, Chang A, Roos C, Scott C. Predictors of intention to reduce stroke risk among people at risk of stroke: an application of an extended health belief model. Rehabil Psychol. 2008;53(4):505-12.

64. Lorig K. Outcome measures for health education and other health care interventions. Stanford University: Sage; 1996.

65. Dishman R, Buckworth J. Increasing physical activity: a quantitative synthesis. Med Sci Sports Exerc. 1996;28(6):706-19.

66. Neubeck L, Freedman SB, Briffa T, Bauman A, Redfern J. Four-year follow-up of the choice of health options in prevention of cardiovascular events randomized controlled trial. Eur J Cardiovasc Prev Rehabil. 2011;18(2):278-86.

67. Conn VS, Hafdahl AR, Mehr DR. Interventions to increase physical activity among healthy adults: meta-analysis of outcomes. Am J Public Health. 2011;101(4):751-8. 
68. Jaglal SB, Haroun VA, Salbach NM, Hawker G, Voth J, Lou W, et al. Increasing access to chronic disease self-management programs in rural and remote communities using telehealth. Telemed J E Health. 2013;19(6):467-73.

69. Huijbregts M, McEwen S, Taylor D. Exploring the feasibility and efficacy of a telehealth stroke self-management programme: a pilot study. Physio Canada. 2009;61(4):210-20.

70. Taylor DM, Cameron Jl, Walsh L, McEwen S, Kagan A, Streiner DL, et al. Exploring the feasibility of videoconference delivery of a self-management program to rural participants with stroke. Telemed J E-Health. 2009;15(7):646-54.

71. Taylor D, Stone S, Huijbregts M. Remote participants' experiences with a group-based stroke self-management program using videoconference technology. Rural Remote Health. 2012;12(2):1-15.

72. Jacobs RJ, Lou JQ, Ownby RL, Caballero J. A systematic review of eHealth interventions to improve health literacy. Health Inform J. 2014; doi:10.1177/1460458214534092

73. Nutbeam D. Health literacy as a public health goal: a challenge for contemporary health education and communication strategies into the 21st century. Health Promot Int. 2000;15(3):259-67.

\section{Submit your next manuscript to BioMed Central and take full advantage of:}

- Convenient online submission

- Thorough peer review

- No space constraints or color figure charges

- Immediate publication on acceptance

- Inclusion in PubMed, CAS, Scopus and Google Scholar

- Research which is freely available for redistribution 